\title{
CONSTRUINDO UM PROJETO DE PESQUISA: PAISAGENS INDUSTRIAIS EM GERMI- NAL DE ÉMILE ZOLA
}

\author{
Rodrigo Janoni Carvalho ${ }^{1}$
}

${ }^{1}$ Mestrando em Geografia pela Universidade Federal de Uberlândia. Bacharel e Licenciado em História pela mesma instituição. Universidade Federal de Uberlândia. E-mail: rudrigu7@gmail.com

Recebido em 07/2013. Aceito para publicação em 10/2013.

Versão online publicada em 12/09/2014 (http://seer.ufrgs.br/paraonde)

\begin{abstract}
Resumo - A produção do escritor naturalista francês Émile Zola (1840-1902) é considerada um marco na literatura por sua tentativa de aproximar a arte do saber científico vigente, conforme os preceitos de seus romances experimentais. A repercussão do autor, sobretudo no mundo ocidental, não se deu somente às suas obras: seu destaque se revela no elevado engajamento político como figura libertária. Germinal (1885) constitui um exemplo de sua maestria escritural, em que os mundos burguês e proletário e seus planos ideológicos, sociais e culturais se embatem num romance enervante. Zola tece um retrato da atmosfera pesada e suja que presenciou, relevando ao leitor imagens tão fortes e vivas que extrapolam sua característica de ficção. A presente investigação visa analisar a paisagem urbano-industrial representada pelo autor e seus conteúdos geográficos, promovendo um resgate do fenômeno industrialismo e suas inter-relações com as transformações sociais e espaciais. Nosso escopo central abarca a coexistência da miséria humana e da riqueza material, tomando a produção literária enquanto denúncia social. Essa discussão é fruto da nossa pesquisa para a construção de um projeto de mestrado.
\end{abstract}

Palavras-chave: : Geografia Histórica. Geografia Urbana e Industrial. Geografia e Literatura. Germinal (1885). Émile Zola (1840-1902).

\section{INTRODUÇÃO E JUSTIFICATIVA}

A presente investigação visa analisar a paisagem urbana e industrial representada na obra Germinal do escritor francês Émile Zola e os seus conteúdos geográficos, realizando um resgate do fenômeno industrialismo e suas inter-relações com as transformações sociais e espaciais. Nossa problemática abarca a coexistência da miséria humana e riqueza material, tomando a produção literária enquanto denúncia social. As mudanças da sociedade industrial infestaram a atmosfera intelectual, tornando a Literatura um campo privilegiado de estudo.

Partimos da categoria paisagem para compreensão dos lugares da narrativa, a partir de incursões históricas. Na medida em que a Revolução Industrial provocou profundas mudanças nas configurações socioespaciais do mundo capitalista, grande parte dessas considerações pode ser resgatada no discurso de Zola. Nesse sentido, podemos avaliar a gênese e o desenvolvimento da atividade industrial, os processos de industrialização no mundo ocidental e a espacialização urbana. A discussão vai ao encontro de temas da Geografia Urbana e Industrial, Geografia Histórica e a interface Geografia e Literatura.

A ampliação do horizonte geográfico se fez sentir no domínio da literatura, contando com a riqueza acerca das cidades, lugares, paisagens e regiões. Nesse direcionamento fazem parte os estudos das percepções, cognições e representações do ambiente geográ- fico, das paisagens, do sentido dos lugares, dos gêneros de vida e da literatura (AMORIM FILHO, 2008). Para a finalidade da presente investigação, ressaltamos a importância das literaturas na nova Geografia enquanto questão primordial.

Consideramos o tempo e o espaço como referências indissociáveis, fenômenos inter-relacionados e simultâneos, tomados como categorias universais e históricas, respectivamente. As questões que a Geografia coloca para o entendimento do movimento do real da sociedade não podem ser apenas as do presente. Conforme Rui Erthal (2003), a Geografia, ao se colocar como conhecimento preocupado com a dimensão espacial da sociedade, não pode esquecer que os fenômenos sociais são, também, temporais, sendo a Literatura representação discursiva legítima no resgate de configurações temporais e espaciais.

[...] papel fundamental deve ser dado à chamada geografia histórica, que, além de se preocupar em recuperar as espacialidades pretéritas que marcam as espacialidades atuais, busca metodologias apropriadas e esforça-se em refletir a categoria tempo, a fim de fornecer subsídios à abordagem espacial e temporal (ERTHAL, 2003, p. 30).

Os textos literários colocam-se como um valioso material, sobretudo por sua evocação da atmosfera dos lugares e do cotidiano social. Ao recorrermos à obra literária, resgatamos contribuições com retratos 
de fragmentos do espaço em transformação, articulando vivências e experiências. Consoante Frederico Barcellos, o interesse pela interface Geografia e Literatura possibilita que várias tendências se tornem matéria de reflexão, seja em relação à crítica social, quanto em relação ao que está em jogo nos discursos da representação socioespacial.

[a literatura] teria importância para o estudo geográfico, por transcrever as experiências concretas que o autor tem com os lugares, sendo vista assim como resultado de percepção da qual guardará o vestígio. 0 romance é visto como o encontro entre o mundo objetivo e a subjetividade humana [...] o romance funciona como testemunho de pessoas reais que ele põe em cena por meio de ficção (BARCELLOS, 2009, p. 43).

Dessa forma, o romance se constitui como um espaço privilegiado de expressão dos conflitos sociais e ideológicos, composto de contradições elaboradas pelo autor a partir de dadas situações existentes em seu horizonte de vivências. 0 naturalismo literário se pauta como romance de excelência nesse quesito por seu rigor metodológico. Ao combinar teorias polêmicas como o darwinismo, o evolucionismo e o determinismo científico, Émile Zola inovou com sua escrita conhecida como romance experimental. Em contraposição ao romantismo, que esbanjava a face idealizada da vida, os realistas acreditavam na necessidade de se retratar o cotidiano massacrante, egoísta e miserável.

A estética surge na segunda metade do século XIX com a conjugação de fatores recorrentes ao industrialismo: as contradições sociais e o desenvolvimento das ciências. Buscava-se retratar a realidade aprofundando-a em suas mazelas sociais como os vícios, as paixões, os sentimentos torpes e animalescos, considerados baixos e sujos, sendo um recorte social em termos gerais da vida burguesa e proletária. A outra face do lucro e da industrialização foi marcada pela miséria, a convivência com lixo e esgotos a céu aberto e a crueldade do sistema fabril com a desagregação da família operária. Diante das profundas transformações da vida social, insistentes preocupações como a Literatura acompanharam as discussões teóricas em torno dos efeitos do industrialismo.

$\mathrm{Na}$ pretensão de tecer considerações acerca do espaço geográfico, sabemos que a paisagem enquanto categoria de análise é essencial à Geografia, abarcando processos naturais e sociais como associação de múltiplos fenômenos. Destacam-se ainda outras categorias correlacionadas e com suas particularidades: espaço, lugar, território e região. Com intuito de compreendermos o contexto histórico em questão, a paisagem será reveladora dos elementos da sociedade industrial.

Segundo Carl Troll (1997), a paisagem seria o resultado da dinâmica interacional entre aspectos humanos e naturais, imbricada de significados, simbologias e valores. A proposta de Troll implica uma visão holística e transdisciplinar, unificando a geosfera com os artefatos tecnológicos. Para Bertrand e Bertrand (2007), a paisagem é reflexo e marca impressa da sociedade dos homens na natureza; parte de nós mesmos, ferramenta e cenário; evolui, é móvel e frágil; nem estática, nem condenada. É, portanto, um produto social materializado pela mediação sociedade e natureza. A paisagem é uma representação.

Naturalismo como expressão da sociedade industrial. É com base nessa ideia que a investigação se fundamentará, mapeando o cotidiano da cidade ocidental mediada pela expressão literária, desvendando as formas, os conteúdos e as estruturas da paisagem e se traduzindo numa análise do homem no espaço num determinando recorte histórico. Propomos pensar a denúncia das mazelas sociais a partir de uma situação geográfica pretérita, reforçando o caráter multidisciplinar do Programa e promovendo o desenvolvimento dos estudos geográficos com uma proposta relativa à compreensão da sociedade e do espaço. Justifica-se, portanto, a necessidade deste trabalho enquanto contribuição aos estudos geográficos.

\section{PROBLEMÁTICA}

0 romance nos interessa como uma resposta ficcional possível do recorte histórico a ser analisado enquanto representação artística dotada de questões pertinentes. A obra literária funciona como testemunho de pessoas reais que ela põe em cena por meio de ficção através da análise do escritor, considerado um intelectual e indivíduo expressivo (GOLDMANN, 1976). Convidamos o leitor a experimentar e sensibilizar-se com o estudo a ser realizado, sobretudo, compreender uma parcela do que é o "inferno paleotécnico", nas palavras de Lewis Mumford, oriundo das profundas transformações espaciais e sociais da coexistência entre a miséria e a riqueza material na sociedade industrial.

Na pretensão de analisar os elementos constituintes da paisagem industrial oitocentista, a partir da obra Germinal e dos seus conteúdos geográficos, faz-se necessário o levantamento de questionamentos. A obra de Émile Zola é a história da luta entre o herói operário e a mina Voreux devoradora de homens. Em francês, o nome da mina sugere voracidade, sem tradução para o português. Contudo, é interessante notar que os tradutores conseguiram transmitir a sensação voraz, permitindo conservar intacta a relação entre o nome da mina e sua agressividade em "comer" homens (PONCIONI, 1999, p. 66-67).

Visamos analisar a visão de mundo do escritor e a sua análise do espaço, realçando uma espécie de "espaço agente" pela voracidade da mina. Nessa perspectiva, podemos ler a paisagem industrial, tendo em vista as descrições do ambiente das minas de carvão enquanto contribuição no resgate do cenário acerca da principal fonte de energia do industrialismo em sua fase de ex- 
pansão espacial. 0 realismo de Zola se traduz na inserção de lugares reais e na criação de fictícios, bem como na capacidade de sintetização das agitações do movimento operário que se sucederam durante a segunda metade do século XIX. A verossimilhança também foi obtida através da precisão dos meios sociais, da convivência e da lealdade e objetividade de suas descrições. Zola descreve detalhadamente as construções da paisagem do complexo minerador:

[...] ao nível do solo, outro espetáculo o fazia parar. Era uma massa pesada, um amontoado de construções de onde se levantava a silhueta da chaminé de uma fábrica. Raros clarões saíam das janelas sujas, cinco ou seis lampiões tristes pendiam do lado das vigas de madeira enegrecidas do edifício, alinhando vagamente perfis de cavaletes gigantescos. E, dessa aparição fantástica, engolfada na noite e na fumaça, um único ruído se elevava: o arfar grosso e prolongado de um escapamento de vapor, que não se via. [...] começava a perceber cada uma das partes da mina, o galpão preto onde $o$ carvão é peneirado, a torre do sino do poço, a vasta casa da máquina de extração, o torreão quadrado da bomba de esgoto. [...] uma chaminé que mais parecia um chifre ameaçador, dava-lhe a impressão de um animal voraz e feroz, agachado a espreita para devorar o mundo (ZOLA, 2007 [1885], p. 14-15) (grifo nosso).

A percepção de Zola nos remete ao visual, às interpretações, ao processo, ao fenômeno do industrialismo. Em Germinal, Montsou é um lugar fictício próximo à cidade de Marchiennes localizada no norte da França, sendo a principal localidade ao longo da narrativa. Essa localidade nos remete àquele novo tipo de cidade que Charles Dickens, em Tempos Difíceis, chamou de Coketown, em alusão às cidades industriais inglesas. Como enfatiza Lewis Mumford, entre os anos de 1820 e 1900, a destruição e a desordem nas grandes cidades são semelhantes ao campo de batalha. Em grau maior ou menor, todas as cidades do mundo ocidental foram marcadas com características arquetípicas de Coketown, de modo que essa expansão se articula com temporalidades e configurações pré-existentes, gerando algo único, isto é, uma formação socioespacial. 0 extenso que a atividade industrial e a urbanização adquirem vai ao encontro da definição proposta por Carlos Santos (1986):

[...] a instrumentalização da natureza, dos recursos naturais, do espaço, dos homens, que também são recursos, também são espaço, dentro do processo de divisão social do trabalho [...] tornando-a [natureza] espaço de expressão humana, em diferentes níveis tecnológicos, na construção de artefatos que refletem funções exclusivamente humanas (abrigo, alimento e circulação). Tais objetos-finalidades preenchem os lugares e, consequentemente, fazem geografias (SANTOS, 1986, p. 29).

Em Coketown, o império do tempo útil não deixa espaço aos devaneios: as pessoas não vinculadas à produção estão sempre de passagem ou são marginais. 0 industrialismo, a principal força criadora do século XIX, produziu o mais degradado ambiente urbano que o mundo jamais vira; até mesmo os bairros das classes dominantes eram imundos e congestionados (MUMFORD, 1991, p. 484). No caso de Germinal, dois nomes constantes de cidades são reais: Marchiennes e Lille. Montsou, criada por Zola, é, com efeito, uma alusão às diversas localidades francesas onde aconteceram greves importantes na segunda metade do século, semelhante à Coketown. A mina de Zola, voraz e capaz de engolir tudo a sua volta, grande personagem do enredo, vai ao encontro da cidade carbonífera, predominantemente negra, cinzenta e sombria, apontada por Mumford.

A noite estendia-se por sobre a cidade carbonífera: a sua cor predominante era o negro. Nuvens negras de fumo rolavam das chaminés da fábrica e dos pátios ferroviários, que muitas vezes penetravam dentro da cidade, poluindo o próprio organismo, a espalhar fuligem e cinzas por toda parte. [...] Sombrio, descolorido, acre, malcheiroso - assim era o novo ambiente (MUMFORD, 1991, p. 509-510).

Nesse panorama, ressaltamos a importância da paisagem enquanto resultado da observação de que todos os geofatores, inclusive a economia e a cultura, se encontram em interação, distinguindo-se as paisagens naturais das culturais segundo a importância da intervenção do homem (TROLL, 1997). Propomos pensar a mina de carvão enquanto uma "célula" da paisagem industrial, conforme conceituação de Troll, sendo imprescindível compreendermos o referido espaço enquanto constituinte do processo de industrialização.

A acentuação da transformação espacial durante os séculos XVIII e XIX, com ênfase no modelo capitalista, nos permite apontar o surgimento da paisagem industrial. Consideramos a conceituação dessa categoria, de modo que pretendemos contribuir com nuances em sua definição. Nesse exercício, precisamos notar o que é revelado e incorporado pela categoria; desmontarmos o que vemos; percebermos as diferentes temporalidades presentes e quais os vínculos revelados. Devemos problematizar além de sua materialização, pontuando os símbolos, significados e representações diante de um conjunto dinâmico de arranjos da sociedade.

Como a Geografia pode se apropriar de discursos literários e utilizá-los como fonte baseando-se em categorias para fundamentar a análise dessas representações? Como a paisagem pode ser usada para decifrar 
os processos de industrialização? Como a natureza, a cidade, a humanidade e a técnica aparecem nessas paisagens? Como o espaço francês é caracterizado?

Como a produção industrial originou um novo proletariado - os operários mineradores? Em que medida o progresso gerou desarticulação social e ameaça de aniquilamento do habitat das pessoas? De que maneira a paisagem urbana foi transformada face ao demasiado crescimento demográfico? Como o movimento intermitente e ritmado dos homens afetou a lógica da natureza ao tempo útil? Como esses temas são apresentados na obra que vamos estudar?

De que forma podemos avaliar a estetização da pobreza documentada em ilustrações e literaturas? A paisagem revela os pesadelos do sistema fabril e a desagregação da família operária? Como as habitações industriais são descritas? Quais as condições sanitárias? De que forma Zola denuncia a degradação ambiental? Percebemos no romance a ausência de plantas e a presença de paisagens monótonas e degradadas, condizente à rápida transformação de amplas áreas florestais em minas de exploração e monoculturas.

Como são os indivíduos da trama? A partir de suas personagens e do jogo de oposições, Zola faz um retrato patológico da coexistência dos "bolsões de miséria" com os "palácios da indústria”, descrevendo a puberdade dos mineiros (que mais parecem adultos) e a juventude burguesa (tratada como infantil).

Quais são as condições de trabalho na cidade subterrânea? 0 transporte do carvão constitui uma tarefa extremamente árdua em corredores baixos e de chão irregular, empregando-se meninos ou moças, como podemos observar em Germinal. Este ambiente constitui um prolongamento e uma normalização que o minerador é obrigado a aceitar desligado das condições naturais, submetido ao controle mecânico, às limitações artificiais das reações humanas, da iluminação e da ventilação. Questionamos se as condições artificiais e a existência encasulada nas cidades subterrâneas justificariam a crença do progresso humano.

Pela riqueza dos detalhes parece que o livro foi escrito por um carvoeiro francês do século XIX, caso fosse verossímil imaginar tal condição naquelas circunstâncias. Zola se propôs a traduzir o grito dos proletários explorados e sufocados pelo pó negro da hulha, a grande mola propulsora do industrialismo. Zola não levou somente ao conhecimento de seu público leitor o retrato das condições insalubres e da miséria, como também expôs sua leitura sensível, profunda e engajada desse cenário, inspirado na luta dos mineiros franceses.

Nessa perspectiva, como o autor descreve, descobre e revela o contraditório na paisagem? Consideramos notório o seu método ao deixar entrar luz em lugares obscuros de forma realista. Ressaltamos a literatura como meio de descoberta de mundos, continuidade de experiências, ampliação do nosso universo e incitação à imaginação de outras maneiras de conceber, organizar e sentir ao abrir possibilidades de interação com os outros, enriquecendo-nos. Ela nos proporciona sensações insubstituíveis que fazem o mundo real se tornar mais pleno de sentido.

\section{OBJETIVOS GERAIS E OBJETIVOS ESPECÍFICOS}

O objetivo geral da investigação é analisar a paisagem industrial representada na obra de Émile Zola e os seus conteúdos geográficos, promovendo-se um diálogo multidisciplinar, na perspectiva de que este é um dos pilares do Programa. Pretendemos realizar um resgate histórico-geográfico do fenômeno do industrialismo e suas inter-relações com as transformações sociais e espaciais. Elencamos os seguintes objetivos específicos que contemplarão a sua maneira o principal, podendo se traduzir em possíveis capítulos ao longo da pesquisa:

1. Analisar o industrialismo e a transformação espacial, a partir da paisagem industrial (Coketown/ Montsou): o encontro do contraditório em Zola (jogo de oposições); as descrições acerca do espaço, da paisagem e do lugar; "habitat para a carne humana" (cortiços); os agentes geradores da cidade (mina, indústria e ferrovia); a insalubridade urbana e outros temas.

2. Compreender o processo em questão a partir da análise das minas de carvão como uma "célula da paisagem" industrial (nos termos de Carl Troll), enquanto espaço essencial daquele contexto: a vida enclausurada do minerador ("asfixiante labor"); o uso da mão de obra infantil e de mulheres nos veios carboníferos; o papel das técnicas nas condições artificiais; a insegurança e a falta de regulamentações trabalhistas; a hierarquia, a disciplina e a divisão de tarefas no regime fabril; dentre outros temas.

3. Aprofundar os conhecimentos acerca da sociedade industrial e das condições de vida e trabalho: os sujeitos (visão dicotômica e a questão patológica no retrato dos proletários e burgueses); o "rosário de desgraças" da família operária (injustiças, sofrimentos, embates, degradação moral, desestruturação social); as "germinantes divergências" no movimento operário e as caricaturas dos pensadores da época; a "civilização incinerada" e a "horda de famintos e miseráveis" (o contraste - pobreza humana e riqueza material industrial) e a germinação pela esperança e resistência.

Pensando a investigação enquanto contribuição aos estudos geográficos e suas interfaces:

4. Pretendemos ressaltar a relevância da categoria paisagem no entendimento do espaço geográfico segundo as transformações do uso e ocupação humana; elaborar uma análise integradora de elementos que compõe a categoria em seus aspectos naturais e sociais; contribuir com os estudos geográficos na ampliação do 
horizonte de pesquisa, a partir dos diálogos com a literatura e a história, enriquecendo o entendimento sobre a categoria paisagem urbana e industrial; dialogar com fontes primárias complementares à obra literária escolhida (pinturas, fotografias, filmes, documentos de época, relatos de viagens e outros), ampliando as formas de construção da geografia histórica.

\section{REFERENCIAL TEÓRICO-CONCEITUAL BÁSICO}

0 referencial teórico proposto para a investigação inicia-se com a análise de Germinal (1885), com o suporte em contribuições acerca do naturalismo, do contexto histórico e das transformações do espaço. Para compreensão literária utilizaremos: Do Romance - 1881 e 0 Romance Experimental - 1880 do próprio Émile Zola; Alfredo Bosi - História Concisa da Literatura (2006); Antonio Candido - Literatura e Sociedade (1985); Arnold Hauser - História Social da Arte e da Literatura (1982); Cláudia Poncioni - Émile Zola em português (1999); Eduardo Silva - A obra de Émile Zola no Brasil (1999); Francisco Caudet - Prólogo da versão espanhola de Germinal (1994); Henri Mitterand - Émile Zola - entre a genialidade e a justiça (2006) e Zola à Anzin: les mineurs de Germinal (2002); Marília Rodrigues - Medicina experimental e hereditariedade no naturalismo de Émile Zola (2009) e outros.

Destacamos as contribuições entorno da Geografia Histórica, como as análises de Maurício de Abreu - Construindo uma geografia do passado (2000) e Marcelo da Silva - A Geografia e o estudo do passado (2012). Consideramos, também, os estudos de Milton Santos no que tange o espaço geográfico e as relações entre tempo e espaço em A Natureza do Espaço (2008), Por uma geografia nova (1980), Pensando o espaço do homem (2004) e Técnica, Espaço, Tempo (2008).

Visando compreender o fenômeno do industrialismo destacamos Edward Thompson - A formação da classe operária inglesa (1987); F. Engels - A situação da classe trabalhadora na Inglaterra (1845); F. Béguin - As maquinarias inglesas do conforto (1992); L. Mumford - A cidade na história (1991); M. Bresciani - Londres e Paris no século XIX (2004); K. Polanyi - A grande transformação (2000); Eric Hobsbawm - A Era das Revoluções (1977), A Era do Capital (1996) e Os Trabalhadores (1981); M. Perrot - Os excluídos da história (1988); D. Clark - Introdução à geografia urbana (1985); P. George - Geografia industrial do mundo (1963); P. Mantoux - A revolução industrial no século XVIII (1988); e outros.

Reforçamos que os enfoques espacial e temporal isolados são ambos insuficientes, fazendo-se necessário um enfoque espaço-temporal, pois "tudo o que existe articula o presente ao passado, pelo fato de sua própria existência" (SANTOS, 1980, p. 205). Vale ressaltar os seguintes apontamentos metodológicos no estudo de espaços pretéritos: a) as variáveis que operacionalizam as categorias geográficas não são universais e re- querem adequação ao contexto do passado em exame; b) o "presente de então" só pode ser compreendido à medida de sua contextualização; e c) há de se investir em levantamento bibliográfico referente ao tempo que se queira estudar e realizar incursões em instituições que guardam a memória dos acontecimentos (ABREU, 2000, p. 18).

\section{METODOLOGIA}

Partiremos da paisagem industrial para se chegar ao conhecimento de um processo que revele as relações dos elementos formadores da sociedade em que vivemos. Conforme indicamos, numa investigação geográfica que se coloca como análise de um espaço pretérito, há de se considerar a relevância da contextualização e o investimento no levantamento bibliográfico. Colocamos a relevância da incursão histórica enquanto exercício metodológico.

Nesse trabalho, colocamos à tona a noção de situação geográfica, esboçada por Maria Laura Silveira (1999), sobretudo pela proposta de estudo tratar de situações geográficas pretéritas, enquanto recorte da história contemporânea. A ideia de situação geográfica surge como uma "janela", de onde podemos ver o movimento conjunto e permanente dos sistemas de objetos e de ações. Trata-se de uma construção histórica composta de atividades convergentes e divergentes, produtos de alianças e conflitos em permanente devir, a partir dos objetos e ações que compõem o espaço geográfico, sendo, portanto, formas de acontecer solidário.

Os eventos criam, de um lado, uma continuidade temporal, suscetível de ser cindida em períodos significativos e, de outro, uma coerência espacial que é dada pelos sistemas de eventos nos lugares. Constrói-se, a cada momento histórico, uma extensão dos fenômenos no lugar, que é uma manifestação da coerência do real (SILVEIRA, 1999, p. 22) (grifo nosso).

Nesse sentido, a situação geográfica conjuga-se com um sistema de ideias, correspondendo num esforço de seleção e hierarquização, de modo que o geógrafo deve escolher os elementos que lhe parecerem fundamentais no complexo de relações. Analisaremos o fenômeno industrial e suas implicações no espaço. Reconhecemos na situação geográfica pretérita o encontro contraditório de valorizações dadas pelos diferentes segmentos da sociedade aos sistemas técnicos, objetos, ações, normas, agentes, escalas, ideologias, discursos e imagens, sendo todos diversos no processo histórico e nos lugares.

Nesse intuito, destacam-se as noções de periodização e de evento, esboçadas por Milton Santos. Para o autor, cada um dos períodos representa uma modernização tecnológica, significando a generalização de uma 
inovação vinda de um período anterior ou da fase imediatamente precedente. Isto é bastante notório com o desenvolvimento capitalista. Associado à periodização, temos o evento, capaz de mudar as coisas e transformar os objetos. Os eventos históricos supõem a ação humana e possuem uma extensão ou espacialidade.

A cada modernização, o sistema tende a desdobrar sua nova energia para os subsistemas subordinados. Isto representa uma pressão para que, nos subsistemas atingidos, haja também modernização. No sistema "dominado", aqui chamado subsistema, as possibilidades de inovação estão abertas, assim, às variáveis que foram objeto de modernização no sistema "dominante" (SANTOS, 2008, p. 31).

Segundo Santos (2008), através das periodizações e do estabelecimento de recortes temporais, podemos trabalhar com o tempo de maneira satisfatória, com ênfase para os estudos da Geografia Histórica. Faz-se necessário articular as diversas escalas envolvidas no estudo de determinada área ou determinado recorte temporal, de modo que percebemos a associação de um tempo interno (do lugar) e um tempo externo (do mundo), de acordo com Milton Santos.

Nesse sentido, o conceito de formação socioespacial e a ideia de "longa duração" aos acontecimentos históricos são essenciais. Observamos na análise a introjeção de uma específica noção de tempo que se releva plenamente em seu sentido moderno com a produção fabril, sintetizando as mudanças sofridas pela organização espacial, produtiva e social com o industrialismo. A primeira metade do século XIX foi marcada pela quebra de vínculo das atividades urbanas com o tempo da natureza. Essa transformação foi indispensável para a constituição da sociedade industrializada. Essa específica noção de tempo...

[...] arranca o homem da lógica da natureza, dos dias de duração variada de acordo com as tarefas a cumprir no decorrer das diversas estações do ano, e o introduz ao tempo útil do patrão, o tempo abstrato e produtivo, o único concebido como capaz de gerar abundância e riqueza, e, mais importante ainda, o único capaz de constituir a sociedade disciplinada de ponta a ponta. Em obediência ao seu contínuo e irreversível fluxo, a repetição diária dos mesmos percursos em direção às mesmas tarefas em momentos previsíveis desse evolver linear, a sociedade do trabalho se institui e elabora sua própria imagem (BRESCIANI, 2004, p. 17-18).

0 recorte espaço-temporal delimitado nessa pesquisa é o norte francês oitocentista, composto por cidades reais e pela fictícia Montsou. Independente da existência dos ambientes da trama, a análise perpassa o recorte regional, ampliando-se para todo o mundo ocidental, com a espacialização do industrialismo, portando-se como uma interpretação daquela sociedade.

Diante dos apontamentos, a fim de atingir os objetivos dessa investigação serão realizados levantamentos, leituras e análises da bibliografia supramencionada, enquanto ferramentas metodológicas. Propomos analisar a obra literária e relacioná-la com a Geografia, a partir da obra em si, como também da vida do autor e do contexto histórico, considerando as visões do mundo do intelectual, segundo apontamentos de Lucien Goldmann. Ademais, no entendimento de uma determinada organização territorial num dado tempo, a literatura se porta como uma considerável ferramenta na análise de tensões existentes em uma sociedade.

Face ao exposto, o trabalho entre a Geografia e a Literatura só tem a enriquecer o conhecimento sobre um recorte histórico, sobre um estilo literário, sobre a vivência do homem no espaço e as suas construções sociais. A literatura é uma fonte repleta de signos, de simbologias, de descrições da realidade. E, a análise de cunho histórico-geográfico, coloca-se como tradução destas simbologias, trazendo não apenas para a Geografia, mas para o conhecimento humano, o que é relevante nas obras literárias.

Além de Germinal, trabalharemos também com outros documentos como a adaptação cinematográfica de Claude Berri (1993); ilustrações da versão original do livro; a leitura da paisagem industrial do historiador Alexis de Tocqueville (1835); Daens - obra cinematográfica de Stijin Coninx (1992) sobre o processo de industrialização na Bélgica; mapas afetos ao industrialismo; informações em jornais contemporâneos disponíveis em versão digital na Biblioteca Nacional da França; pinturas, fotografias e documentos de época; estudos e ilustrações de áreas pobres de Londres de Gustave Doré e as impressionantes fotografias de crianças trabalhadoras do sociólogo Lewis Hine.

Pretendemos aperfeiçoar o olhar sobre Zola, elaborando um quadro biobibliográfico, destacando dados, publicações e fatos relevantes. Destacamos que a proposta de trabalho se projeta como contribuição nos estudos geográficos, com intuito de analisar um fenômeno ímpar na história da humanidade e aprofundar os estudos sobre um intelectual de renome. Aliás, este trabalho se constitui peculiar pela inexistência de estudos assim aprofundados.

Vale ressaltar também a estrutura dinâmica e flexível do Programa de Pós-Graduação em Geografia. Esta proposta fundamenta-se no caráter multidisciplinar do curso considerando o seu Regulamento. Enfatizamos os objetivos do próprio programa perpassando a "formação de docentes, pesquisadores e recursos humanos especializados na área de abrangência da Geografia", promovendo-se pesquisas em prol do desenvolvimento dos estudos geográficos, da melhoria do ensino e do diagnóstico de problemáticas de interesse da área geográfica e afins, possibilitando, assim, "pesquisas in- 
tegradas em torno de questões relativas ao estudo da sociedade e da natureza, ou em campos que as envolvam $^{1 "}$.

Ademais, acreditamos que os textos literários devem ser utilizados como material a ser interpretado sobre as diversas representações do espaço, sendo que nossa investigação constitui uma - e não a única - dentre as variadas possibilidades de análise da obra de Émile Zola, isto é, um estudo sobre uma resposta ficcional possível dentro de um recorte histórico e uma leitura do fenômeno do industrialismo. Nessa perspectiva, verificaremos nas entrelinhas da obra literária as posições e visões de mundo do intelectual acerca de um espaço em transformação, consolidando um estudo sustentado nos pressupostos discorridos, visando o entrelaçamento entre a Geografia, a História e a Literatura.

\section{REFERÊNCIAS}

ABREU, Maurício de Almeida. Construindo uma geografia do passado: Rio de Janeiro, cidade portuária, século XVII. In: GEOUSP (São Paulo/USP), v. 7, p. 13-25, 2000.

AMORIM FILHO, Oswaldo Bueno. Literatura de Explorações e Aventuras: As "Viagens Extraordinárias" de Júlio Verne. In: Sociedade \& Natureza (UFU), n. 20 (2), p. 107 119, dez./2008.

BARCELLOS, Frederico Roza. Espaço, Lugar e Literatura O olhar geográfico machadiano sobre a cidade do Rio de Janeiro. In: Espaço e Cultura (Rio de Janeiro/UERJ), n. 25, jan./jun., 2009, p. 41-52.

BERTRAND, Georges e BERTRAND, Claude. Uma Geografia transversal e de travessias: o meio ambiente através dos territórios e das temporalidades. Maringá: Ed. Massoni, 2007.

BRESCIANI, Maria Stella Martins. Londres e Paris no século XIX: o espetáculo da pobreza. $10^{\underline{a}}$ reimpressão da $1^{\mathrm{a}}$ ed. de 1982. São Paulo: Brasiliense, 2004.

CARVALHO, Rodrigo Janoni. Émile Zola e o naturalismo literário. In: Urutágua (Maringá), v. 24 - mai./ago., 2011a, p. 105-118. Disponível em <http://periodicos.uem.br/ ojs/index.php/Urutagua/article/view/12727/7169>. Acesso em 27 out. 2013.

Estética naturalista como expressão da sociedade industrial: uma leitura da obra Germinal de Émile Zola. In: Série Monografias, 1aㅡ ed., v. 1. CD-ROM. Uberlândia: Pró-Reitoria de Graduação/Universidade Federal de Uberlândia, 2012, p. 454-576. ISSN 2316-7939.

ERTHAL, Rui. Geografia Histórica - Considerações. In: Geographia (Niterói/UFF), n. 9, p. 29-39, 2003.

GERMINAL. Direção: Claude Berri. Bélgica, França e Itá- lia: AMLF, 1993. 1 filme (160 min), son., color.

GOLDMANN, Lucien. Ciências Humanas e Filosofia. São Paulo: Difel, 1976.

MUMFORD, Lewis. A cidade na história: suas origens, transformações e perspectivas. Tradução de Neil R. da Silva. 3aㅡ ed. brasileira. São Paulo: Martins Fontes, 1991.

MURRAY, Alison. Film as Nation Icon: Claude Berri's Germinal. In: The French Review (Carbondale - Illnois - Estados Unidos), Vol. 76, n. 5, April 2003.

PONCIONI, Cláudia. Émile Zola em português: um estudo das traduções de Germinal no Brasil e em Portugal. São Paulo: Annablume, 1999.

SANTOS, Carlos. O conceito de extenso (ou a construção ideológica do espaço geográfico). In: SANTOS, M.; SOUZA, M. A. A. (org.). A construção do espaço. São Paulo: Nobel, 1986.

SANTOS, Milton. A Natureza do Espaço: Técnica e Tempo, Razão e Emoção. 4⿳a ed. São Paulo: Edusp, 2008.

A noção de tempo nos estudos geográficos. In: Por uma geografia nova. Editora Hucitec, São Paulo, 2 $2^{\underline{a}}$ ed., p. 203-212, 1980.

SILVA, Marcelo Werner da. A Geografia e o estudo do passado. Conceitos, periodizações e articulações espaço-temporais. In: Terra Brasilis (Nova Série), nov. 2012. Disponível em <http://terrabrasilis.revues.org/246>. Acesso em 12 nov. 2013.

SILVEIRA, Maria Laura. Uma situação geográfica: do método à metodologia. In: Revista Território (Rio de Janeiro/UFRJ), v. 6, n. 6, p. 21-28, 1999.

TOCQUEVILLE, Alexis de. Viagens à Inglaterra e à Irlanda. Tradução de Plínio Augusto Coelho. São Paulo: Imaginário/Primeira Linha, 2000.

TODOROV, Tzvetan. A Literatura em perigo. Tradução de Caio Meira. Rio de Janeiro: DIFEL, 2009.

TROLL, Carl. A paisagem geográfica e sua investigação. In: Espaço e Cultura (UERJ), n. 2, p 1-7, 1997.

ZOLA, Émile. Germinal. Tradução de Francisco Bittencourt. São Paulo: Martin Claret, 2007 [1885].

Germinal. Paris: Librarie Illustrée, 1885. Disponível em <http://gallica.bnf.fr/ark:/12148/bpt6k5493777b.image.r=Germinal.langPT.f9.pagination $>$. Bibliothèque Nationale de France. Acesso em 20 nov. 2013.

O romance experimental e o naturalismo no teatro. São Paulo: Perspectiva, 1982 [1880].

${ }^{1}$ Conforme o Regulamento do Programa de Pós-Graduação em Geografia (2003), da Universidade Federal de Uberlândia, com destaque

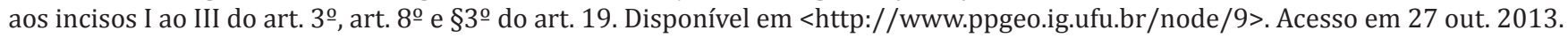




\title{
FORMULATING A RESEARCH PROJECT: INDUSTRIAL LANDSCAPES IN GERMINAL OF ÉMILE ZOLA
}

\begin{abstract}
The production of the french naturalist writer Émile Zola (1840-1902) is considered a landmark in the literature for his attempt to approach the art to the established scientific knowledge, according to the precepts of his experimental novels. The repercussion of the author, especially in the western world, not only gave their works: its highlight is revealed in high political engagement as libertarian figure. Germinal (1885) is an example of his scriptural mastery, where the bourgeois and proletarian worlds and their ideological, social and cultural plans are impinging on an unnerving novel. Zola weaves a portrait of the heavy and dirty atmosphere that he witnessed, revealing to the reader strong and vivid images that surpass their characteristic of fiction. This research aims to analyze the urban-industrial landscape represented by the author and their geographic content, promoting an analysis of the industrialism phenomenon and their interrelationships with social and spatial transformations. Our main scope covers the coexistence of human misery and material wealth, taking the literary production as social denunciation. This discussion is fruit of our research for the construction of a master's project.

Keywords: Historical Geography. Urban and Industrial Geography. Geography e Literature. Germinal (1885). Émile Zola (1840-1902).
\end{abstract}

